\title{
Emotional Quotient and Intelligence Quotient on Behavioral Finance and Investment Performance
}

\author{
Geoffrey A. VanderPal \\ Purdue University Global
}

Investing is increasingly becoming an important way of creating wealth. A successful investment requires one to have proper analytical skills, intelligence, emotional control, and common sense. It also requires investors to behave rationally when making decisions and consider logic rather than emotions or perceptions. The purpose of the study is to examine whether education, emotional quotient, and intelligence quotient have a positive influence on investment performance and decision-making. In addressing the research problem, there is a review of previous literature on the topic. The review provides an understanding of the contribution other authors in understanding the link between EQ, IQ, and education in investment performance and decision-making. According to the findings, EQ has positive effect on the investment decisions and performance. Individuals with high levels of IQ are more likely to take risks than the ones with low IQ. It demonstrates the effects of an individual's cognitive ability on decision-making and investment performance. The research has also indicated that education and experience are critical in making investment decisions.

Keywords: intelligence quotient, emotional quotient, investing, behavioral finance

\section{INTRODUCTION}

\section{Background}

Investment is increasingly becoming an important way of creating wealth. One of the critical aspects of making proper investment decisions is an analysis of the financial and non-financial aspects of a security. The analysis often focuses on the expected returns and ability of an investment to generate the required profits. Ideally, a successful investment requires one to have proper analytical skills, intelligence, emotional control, and common sense. It also requires investors to behave rationally when making decisions and consider logic rather than emotions or perceptions. Emotions and feelings often lead to investment problems. According to Warren Buffet, investors require temperament alongside ordinary intelligence to control the urges that get other people into investment problems. The traditional view of investment decision-making largely focused on the financial aspects such as expected returns and profits. Investors conduct fundamental and technical analysis to understand the suitability of a security for investment. However, risks have also emerged as significant factors to consider when making investment decisions. The level of risks not only affect the investment performance but also influence the decision-making process of investors. Investors will select investment securities based on their risk appetite and potential returns from a portfolio. Exposure to risks often create a low probability on the expected returns from an investment. 
Most investors will prefer investment assets based on their returns, risks, and suitability in achieving the desired outcomes. However, emotions and intelligence levels often influence the investment performance and decisions investors make. Other than consider the rational aspects of an investment, most people will allow their emotions and level of intelligence to influence their decisions. The personality traits of an individual will affect their behaviors and actions in the investment market. Arguably, personality is one of the major psychological factors that influence human behavior. Some of the personality traits that influence the decision-making processes include agreeableness, extroversion, openness, conscientiousness, and neuroticism. The traits will influence the behavior of an individual and decisions in the investment market. For example, the ability to get along with others, interests, creativity, ability to withstand stress, and dependability of an individual influence their actions. The personal traits often play a critical role in the investment decision-making process. Other than the rational actions, the personal traits may override logic, leading to investment decisions that deviate from the reality. As investors consider their personal traits, it is important not to understand the significance of technical and fundamental analysis in the decision-making process.

Emotional quotient (EQ), intelligence quotient (IQ), and education have been fronted as some of the factors that influence investment performance and decisions. Emotional intelligence has been broadly described the ability to recognize, interpret, and productively use emotions in solving problems and making decisions. It also means being aware of one's personal feeling, emotional transformations, and using the feeling to make decisions and solve problem. EQ is significant in making better decisions that will yield positive outcomes for individual investors. It covers the ability to process complex information on an individual's feelings and emotions and using the information to guide thinking and human behavior in the investment decision-making process. Investors are likely to be driven by their emotions based on past performances. For example, bad attitudes on specific stocks from their historical performance will influence the current decisions and ultimately the investment performance. Investors are unlikely to pick the stocks that they have adverse experiences with and choose the ones that have reported strong earnings in the past. Intelligence quotient (IQ) as a cognitive ability to perform a task and make a decision. Individuals with high levels of IQ are more likely to take risks than the ones with low IQ. It demonstrates the effects of an individual's cognitive ability on decision-making and investment performance. Moreover, IQ could also be significant in making better decisions that yield positive investment outcomes. Based on the EQ and IQ background, the current study aims at exploring

\section{Problem Statement and Study Significance}

Successful investments require analytical skills, common sense, emotional control, and intelligence. Traditionally, there has been an overemphasis on the fundamental and technical analysis as the most important processes in the investment decision-making processes. Until the 1970s, there were limited research studies on the effect of psychology, emotions, and other components of behavioral finance on the investment decision-making processes and performance. The studies have demonstrated that emotions and level of intelligence influence the behaviors of most investors, limiting rationality in the decision-making processes. Since most investors are risk-averse, they will make attempts to boost their expected returns through the minimization of portfolio risks or volatility. The psychological factors such as emotions, perceptions, and feelings will influence the decisions on the expected returns and optimal risks an investor can take in the investment market. The emotions of investors are critical in the decision-making processes. However, emotional mistakes could possibly limit portfolio performance by reducing the potential returns from an investment. It reflects the extent to which an investor can control their actions or decisions and accept or reflect an investment opportunity that promise high returns over an investment period. Therefore, a successful investor is one who makes a rational and logical investment decision, controlling emotions and taking position that yield optimal returns over the holding period.

The overdependence on fundamental and technical components of security investment has led to little interest in the effects of emotions, intelligence, and education on investment performance and decisionmaking process. Despite the significance of the psychological factors in behavioral finance, there is little research on the effects of EQ, IQ, and education on investment decisions, and performance. Much of the 
research of EQ and IQ have focused on leadership and managing people, not behavioral finance, according to VanderPal (2014). Few investors appreciate the extent to which their psychological factors and wellbeing can affect the investment returns. In response to the existing gap, the study researches the contributions of IQ, EQ, and education towards effective decision-making and investment performance. The study is significant in appreciating the role of emotions in investment decisions and performance. An understanding of the role can help investors control their emotions when making investment decisions for better outcomes.

\section{Research Questions}

In examining the effect of EQ, IQ, and education as behavioral factors on investment performance and decision-making process, the study will seek to address the following three primary questions developed around the concepts.

1. Does emotional quotient (EQ) have a positive effect on investment performance or decisions?

2. Does the level of education effect investment performance or decisions?

3. Does intelligence quotient (IQ) have a positive effect on investment performance or decisions?

\section{LITERATURE REVIEW}

\section{Effect of Emotional Quotient (EQ) on Investment Performance or Decisions}

Emotion and perceptions are critical components of behavioral finance that significantly influence the decision-making processes of investors. Several studies have been conducted in the past to examine whether emotional quotient positively affects the investment performance and decisions (Tanvir, Sufyan \& Ahsan, 2016; Dhiman \& Raheja, 2018; Sashikala \& Chitramani, 2017; Pirayesh, 2014; Hadi, 2017; Tariq \& Hassan, 2017; Dhiman \& Raheja, 2018). Tanvir, Sufyan, and Ahsan (2016) examined the impact of an investor's emotional intelligence on investment decisions. According to the authors, perceptions and emotions are critical components of emotional intelligence that will decision investment decisions. The findings from the study demonstrated that emotional intelligence is significant in influencing the investment decision-making processes (Tariq \& Hassan, 2017). It is also fundamental in the selection of investment securities or assets for portfolio developments.

The emotions from past experiences, for instance, may override rational thinking when making decisions (Hadi, 2017; Charles \& Kasilingam, 2014). Investors are likely to be driven by their emotions based on past performances. For example, bad attitudes on specific stocks from their historical performance will influence the current decisions and ultimately the investment performance. Investors are unlikely to pick the stocks that they have adverse experiences with and choose the ones that have reported strong earnings in the past (Alquraan, Alqisie \& Al Shorafa, 2016). Moreover, Tanvir, Sufyan, and Ahsan (2016) argued that investors exhibit motivation, self-awareness, empathy, and self-management when making investment decisions. They are unlikely to pay attention to relationship management as a critical determinant of investment performance.

Hadi (2017) also contributed to the topic by examining the effects of emotional intelligence on investment decision-making from the perspective of financial literacy. Using data gathered from 160 investors, the researcher established a positive and significant nexus between investment decision-making and emotional intelligence. The study also establishes a significantly positive link between financial literacy and investment decisions. Financial literacy is an important aspect of behavioral finance. Investors with high financial literacy tend to have an expansive knowledge of the operations and performance of stock markets. The high literacy levels positively influence their decision-making. High levels of emotional intelligence trigger self-control and supports self-awareness of the investment environment. In effect, it contributes to positive investment decisions that recognize the nature of stock performance. According to Hadi (2017), the ability of an individual to control emotions often creates the path towards successful investment decision-making. The intrinsic elements of an individual such as empathy and self-control are helpful in the planning, assessment, and implementation of quality decisions. Hadi (2017) described emotional intelligence as an individual's ability to recognize and appreciate his or her emotions and link with the ones received from the environment one interacts with. Arguably, investors are likely to make 
informed and better investment decisions and record strong performance when they recognize and appreciate their emotions. It helps reduce possible conflicts that may arise during the decision-making process.

Perceptions towards risks are another reflection of an individual's emotional intelligence that significantly influences investment performance and decisions. Tariq and Hassan (2017) examined the influence of risk perceptions on investment behavior. According to the study findings, a significantly positive relationship exists between risk perceptions and investment behavior. However, the behavior will depend on the extent to which one can assume a given level of risks in the investment market. For the riskaverse investors, there is a negative perception about risks, reducing the levels of investment in the stock market. These are the investors who fear taking too many risks due to the possible losses that may arise.

According to Tariq and Hassan (2017), emotional intelligence is an effective moderating in explaining the investment behavior among individual investors in the stock markets. Under the traditional investment models, risk-averse investors will prefer diversification as a strategy for minimizing the levels of risk exposure and enhancing the expected returns. In behavioral finance, investors will focus on stocks they have sufficient knowledge or experience with. For instance, most investors in the international stock markets will prefer domestic assets over foreign ones. It is a reflection of how emotional intelligence guides investment decisions and performance (Dhiman \& Raheja, 2018). Therefore, the relationship between investment returns and risk perception reflects the influence of human behavioral factors on investment decision-making. The ability to recognize emotions and create clear distinctions is useful in making an investment decision.

Sashikala and Chitramani (2017) reviewed investment behavior about the emotional intelligence of individual investors. The authors recognize the possibility of emotions overrunning logic and rationality when making investment decisions. From a review of the previous literature, Sashikala and Chitramani (2017) established that investors will become more emotional when selecting stocks to include in a portfolio. Rational or logical investment decision-making requires emotional stability. Although it has been argued that financial institutions or issuers of investment securities could help in providing better investment options through assessment of the investors' behavior, it is one of the most challenging tasks that the institutions could perform. Based on the concept of behavioral finance and emotional intelligence, investors are more likely to purchase stocks that have posted positive results in the past over the ones previously sold for a loss. The behavior is a reflection of the effects of emotional intelligence in decisionmaking and investment performance. Moreover, individual trades with high emotional intelligence are more likely to engage in excessive trading than the ones with low emotional intelligence. Therefore, emotional intelligence is a critical determinant of investment performance and decision-making (Dhiman \& Raheja, 2018).

According to Pirayesh (2014), the investment decision is one of the critical components of the stock market. Individual and institutional investors make evaluate the fundamental and technical aspects of stocks in making the decisions. However, emotions oftentimes override the need for rationality and logic in the decision-making process. The author also identified emotional intelligence as one of the personal traits that significantly influence investment decisions. It is important in helping investors make rational decisions when selecting stocks or other securities for portfolio investment. The empirical research by Pirayesh (2014) concluded a meaningful and positive link between emotional intelligence and investment decisionmaking. As investors become more skeptical about risks, they tend to apply more emotional intelligence in their decisions to avoid incurring significant losses. Other interpersonal traits such as personality, consistency, and stress management could also influence investment performance and decisions. Therefore, the findings indicate that EQ has a positive effect on investment decisions and performance.

Behavioral finance factors tend to influence stock investment decisions in different ways. Alquraan, Alqisie, and Al Shorafa (2016) sought to address the issue by examining the extent to which specific behavioral finance factors would affect an individual investor's decision-making process. According to the researchers, factors such as overconfidence, loss aversion, and risk perception are some of the critical issues that influence investment decision-making. However, demographic factors such as income, education experience, gender, and age are likely to influence the decision-making processes. Although these factors 
do not present a meaningful relationship, education and experience have been proven to be significant in the decision-making processes and investment performance. Alquraan, Alqisie, and Al Shorafa (2016) discussed several theories that tend to explain the investment decision-making processes and human behavior. For example, the theory of overconfidence will affect an investor's action and perception towards risks. When an investor is overconfident, there is a possibility of underestimating the risk levels and overestimate the ability to control events and accumulate high returns. The under or overreaction exists as psychological processes that occur in an individual.

Boda and Sunitha (2018) argued that the perception and reaction of investors towards economic and political conditions tend to influence their decision-making, particularly when investing in the securities market. The authors outlined several components of investors' psychology that are significant in their decision-making processes and influence the portfolio performance. According to the results, feelings, perceptions, attitudes, and emotions, personality traits, and moods and sentiments are likely to yield behavioral biases that generate significant losses in the investment market. Some of the biases that are likely to arise from the psychological behaviors include cognitive and heuristic biases. Investors will show overconfidence, regret aversion, over-reaction, and herd effect in the stock market when making their decisions. Other issues such as representativeness, availability, anchoring, and gambler's fallacy are also likely to arise, significantly influencing the decision-making processes.

\section{Effect of Intelligence Quotient (IQ) on the Investment Performance or Decisions}

Ackert, Deaves, Miele, and Nguyen (2020) described intelligence quotient (IQ) as a cognitive ability to perform a task and make a decision. According to the authors, existing literature demonstrates that IQ has a significant relationship with the major preference parameters informing the financial decision-making process. Individuals with high levels of IQ are more likely to take risks than the ones with low IQ. It demonstrates the effects of an individual's cognitive ability on decision-making and investment performance. Moreover, IQ could also be significant in making better decisions that yield positive investment outcomes. Ackert, Deaves, Miele, and Nguyen (2020) experimented to evaluate the existence of a significant relationship between emotional stability (emotional quotient) and cognitive ability (intelligence quotient). Moreover, Ackert, Deaves, Miele, and Nguyen (2020) argued that individuals with high IQ are likely to exercise caution when making investment decisions. The cognitive ability supports higher savings and high-risk assumptions, significantly influencing the investment performance and outcomes. People with high IQ also exhibit high levels of patience and less risk averse. The level of patience will influence the type of stocks to include in a portfolio and expected returns over the holding period.

Ackert et al. (2020) presented regression results to demonstrate that IQ explains risk preference in the investment market. According to the findings, risk preference for individual investors will be significantly affected by the cognitive capacity of an individual (Ackert et al., 2020). A review of the relationship from a gender perspective also indicated that men are more likely to take risks compared to women investors. The high-risk preference is also consistent with the traditional view of the relationship. Individual investors with high IQ are less likely to report behavioral biases that affect the investment outcome. It implies the strong cognitive ability to anticipate possible losses and make decisions that will prevent further losses in portfolio investment.

Browning and Finke (2015) described the concepts of cognitive ability of investors and the influence on stock reallocations during the recession. According to the study, old age often results in lower cognitive ability, which reduces their ability to control emotional responses to potential losses. The study further indicated that the cognitive ability of investors is critically insignificant in the stock reallocations and investment performance (Browning \& Finke, 2015). Since most retirees are old age, they experience low cognitive abilities and skills. They are more likely to show high sensitivity to possible losses when making investment decisions. The older investors will exhibit high preferences for safe stocks after a recession (Browning \& Finke, 2015). It implies that the investors will not invest in stocks and instead consider alternative investment vehicles for lower exposure to risks and high expected returns. The study findings demonstrate the significant relationship between the cognitive ability of investors and their investment behaviors and decisions. Browning and Finke (2015) further established a negative relationship between 
the cognitive ability of older investors and allocation away from stocks. It implies that an increase in cognitive ability will reduce the allocation away from stocks. Investors will prefer stock investments due to the high expected returns and risky environment (Browning \& Finke, 2015). However, since the cognitive levels are low, the investors will reallocate their portfolio holdings away from stocks to prevent possible losses.

Disatnik and Steinhart (2015) established a close link between risk aversion, cognitive closure, changes in uncertainties, and investment decisions. The authors recognized the significance of investment decisions in the management of wealth and improving investment performance (Disatnik \& Steinhart, 2015). In an attempt to understand how an individual or institutional investors make decisions, Disatnik and Steinhart (2015) explored the reactions to new information and changes in the market uncertainties. Despite the existence of new information about specific securities on the stock market, investors are still prone to mistakes that could yield significant losses. According to Disatnik and Steinhart (2015) argued that higher need for cognitive closure results in lacking openness to new information in the stock market. In effect, it exposes most investors to risk preferences. Access to new information may also affect the cognitive ability of investors, significantly influencing their decision-making processes and investment performance (Disatnik \& Steinhart, 2015). For example, investors with access to the poor financial history of a company will be skeptical about buying the stocks (Disatnik \& Steinhart, 2015). The skepticism reflected on the investment decision-making processes indicates the behavioral effects of IQ on investment performance and decisions.

The investment performance and decisions are also likely to be influenced by cognitive and psychological biases among investors. Ady (2018) argued that psychological factors influence most investment decisions compared to the technical and fundamental analysis of securities. Since steady and high dividend payment is one of the factors investors will consider when making investment decisions, the historical trends and investors' perceptions towards the securities will influence the decision-making processes and investment performance. Investors are more prone to the illusion of control, overconfidence, and self-attribution as the psychological factors that influence the decision-making process. Arguably, behavioral biases hinder high and strong performance as emotions and perceptions tend to override logic when making investment decisions. Under the concept of behavioral finance, there is a general argument that investors will utilize illogical assumptions largely driven by emotions and past experiences when making critical investment decisions. The immediate and expected emotion of investors will influence their behavior when making investment decisions. For example, potential investors are likely to purchase stocks when they have a feeling of the expected outcomes. If there is a general feeling that the securities will yield negative results in the future, they will abandon the selection for alternative assets. Expected emissions are often evident before the decision-making. Immediate emotion, on the other hand, arises at the decisionmaking time.

Ady (2018) further described different types of cognitive and psychological biases that affect investment performance and decisions. One of the bases covered in the study is the overconfidence bias. According to Ady (2018), overconfidence bias is the belief that is not reflective of one instinct, adjustments, or cognitive ability. Investors will overestimate their investment potential or capabilities of specific securities, negatively influencing the investment outcomes. The belief that an investor is smatter and can access better information than available leads to poor investment performance. Overconfidence can also arise due to lack of experience or investment history, passiveness, and ignorance (Ady, 2018). The findings call for further research on the extent to which an investor's level of education can affect investment decisions and performance. The availability bias as covered in the study arises when investors use the closeness of events to personal lives when making investment decisions (Ady, 2018). Self-attribution bias will also affect the investment actions and performance in the stock or capital markets. The self-attribution results in the assumption of greater risks that could yield negative returns in the long term.

Existing studies have revealed that investors with overconfidence will trade excessively by selecting securities that promise high returns, yet highly risky. Barber and Odean (2001) explored the aspects of overconfidence and stock investment from a gender perspective. According to the scholars, men often demonstrate high overconfidence when making investments compared to their female counterparts (Barber 
\& Odean, 2001). Korniotis and Kumar (2011) also explored age as a factor of investment decisions from the perspective of cognitive ability. As one ages, physical and cognitive abilities tend to decline. Conversely, knowledge and experience may increase with age. The reduction in cognitive abilities makes it difficult for investors to make rational decisions and generate high returns. Christelis, Jappelli, and Padula (2010) investigated the relationship between portfolio choice and the cognitive abilities of investors. According to the authors, the cognitive abilities of investors display a strong and effective relationship with the propensity to invest in stocks. Cognitive abilities are critical in stock investments to the existence of a wide range of information that influences the outcomes. According to Pak and Mahmood (2015), the personality of individual investors is critical in investment decisions and performance. It reflects an investor's IQ or cognitive ability to make investment decisions in different types of investment securities.

\section{Impact of Level of Education on Investment Performance or Decisions}

Education is yet another significant determinant of investment performance and decisions. Hadi (2017) examined the education component from the perspective of financial literacy and its effects on the investment decision-making process. According to the scholar, financial literacy entails skill, confidence, and knowledge that one requires to make informed financial decisions. The study established a positive and significant relationship between literacy and education levels. Highly educated individuals have a better understanding of the investment environment and have the cognitive ability to understand the evolving elements of the financial markets and make better decisions that resonate with the prevailing circumstances (Awais, Laber, Rasheed \& Khursheed, 2016). Besides, the highly educated investors are informed and broadly knowledgeable on several factors that influence the investment outcomes. Therefore, they are more likely to incorporate their knowledge, skills, and confidence when making investment decisions (Boda \& Sunitha, 2018). The education aspect of the investment decision-making process and performance also relates to the social relations with different people in the investment environment. The exposures will significantly influence the development of financial knowledge that is critical in investment decisionmaking processes. Moreover, uneducated individuals or people with low literacy levels are unlikely to participate in stock market investment (Fachrudin \& Fachrudin, 2016). They will depend on their colleagues for information, limiting their independence in the decision-making processes.

The education and experience of an investor are important in the decision-making process and investment performance. Fachrudin and Fachrudin (2016) considered the idea of financial literacy in explaining the extent to which education and experience will influence investment decision-making processes. According to the authors, generating sufficient returns from investments requires making the right decisions from the onset (Fachrudin \& Fachrudin, 2016). However, it is challenging to make the right decisions when an investor has low levels of financial literacy due to low educational achievement and experience. Education is a crucial factor keeping the investors know about the investment environment, whether domestic or international (Fachrudin \& Fachrudin, 2016). The education level will influence the rationality and logic of investors when making decisions (Fachrudin \& Fachrudin, 2016). For example, rather than follow emotions and perceptions, investors are likely to interrogate different factors that influence investment outcomes and make decisions that will yield the best outcome in terms of returns (Fachrudin \& Fachrudin, 2016).

Fachrudin and Fachrudin (2016) created a model to illustrate the direct contribution of education and experience on financial literacy and the effects on investment decisions. A high investment experience often creates expansive financial literacy, which supports investment decision-making processes (Janor, Yakob, Hashim, Zanariah \& Wel, 2017). Based on the findings, the researchers reported a direct and significant relationship between investing decisions and education. They also concluded that investing experiences positively affect decisions and investment performance (Fachrudin \& Fachrudin, 2016). The experiences provide investors with the exposure required to understand different components of the investment market. Talpsepp, Liivamägi, and Vaarmets (2020) also made a significant contribution to the ongoing research by examining academic abilities, education, and stock market performance and decisions. The authors attempted to assess the effect of the education and academic abilities of individuals on their investment decision-making and investment performance. 
The findings suggest that strong academic abilities positively relate to high investment performance. When investors have strong academic abilities, they conduct a comprehensive analysis of the available investment options before making decisions. They are likely to make rational decisions that will generate high returns and create value on investments (Janor et al., 2017). The education and experience of investors also reflected a positive impact on investment performance. Education gives the exposure investors require to inform their decisions and take investment positions (Janor et al., 2017). Therefore, the realization of a strong stock market and investment performance calls for enhanced academic abilities and education of investors for an increased experience and competence in decision-making.

\section{CONCLUSION}

The purpose of the study was to examine the effects of emotional quotient, intelligence quotient, and education on investment performance and decision-making. The first issue addressed in the study is whether emotional quotient (EQ) have a positive effect on investment performance or decisions. According to the findings, EQ has positive effect on the investment decisions and performance. Investors exhibit motivation, self-awareness, empathy, and self-management when making investment decisions. They are unlikely to pay attention to relationship management as a critical determinant of investment performance. High levels of emotional intelligence trigger self-control and supports self-awareness of the investment environment. In effect, it contributes to positive investment decisions that recognize the nature of stock performance. Moreover, the study findings indicated that a significantly positive relationship exists between risk perceptions and investment behavior. However, the behavior will depend on the extent to which one can assume a given level of risks in the investment market. For the risk-averse investors, there is a negative perception about risks, reducing the levels of investment in the stock market. Finally, a meaningful and positive link between emotional intelligence and investment decision-making. As investors become more skeptical about risks, they tend to apply more emotional intelligence in their decisions to avoid incurring significant losses. Other interpersonal traits such as personality, consistency, and stress management could also influence investment performance and decisions.

On the question of whether intelligence quotient affects investment performance and decisions, the findings indicate a positive link. The previous studies demonstrated that IQ has a significant relationship with the major preference parameters informing the financial decision-making process. Individuals with high levels of IQ are more likely to take risks than the ones with low IQ. It demonstrates the effects of an individual's cognitive ability on decision-making and investment performance. Furthermore, financial literacy has been highlighted as an important aspect of behavioral finance. Investors with high financial literacy tend to have an expansive knowledge of the operations and performance of stock markets. The high literacy levels positively influence their decision-making. High levels of emotional intelligence trigger selfcontrol and supports self-awareness of the investment environment. In effect, it contributes to positive investment decisions that recognize the nature of stock performance. As investors become more skeptical about risks, they tend to apply more emotional intelligence in their decisions to avoid incurring significant losses. Other interpersonal traits such as personality, consistency, and stress management could also influence investment performance and decisions. Therefore, the findings indicate that EQ has a positive effect on investment decisions and performance.

The research has also indicated that education and experience are critical in making investment decisions. Highly educated individuals have a better understanding of the investment environment and have the cognitive ability to understand the evolving elements of the financial markets and make better decisions that resonate with the prevailing circumstances. The experiences provide investors with the exposure required to understand different components of the investment market. When investors have strong academic abilities, they conduct a comprehensive analysis of the available investment options before making decisions. They are likely to make rational decisions that will generate high returns and create value on investments. The studies have demonstrated a direct contribution of education and experience on financial literacy and the effects on investment decisions. A high investment experience often creates expansive financial literacy, which supports investment decision-making processes. 


\section{LIMITATIONS AND FURTHER AREAS OF RESEARCH}

Investment decision-making is crucial to the generation of sufficient returns and profits. Most of the existing studies have examined the influence of fundamental and technical analysis on investment decisions and performance. Specifically, a lot of attention has been on the effects of historical stock prices, financial health, and business valuation on investment decisions. The study sought to examine the effects of emotional intelligence and cognitive ability of investors on their decisions and investment performance. From a review of the previous literature, investors are likely to be driven by their emotions based on past performances. For example, bad attitudes on specific stocks from their historical performance will influence the current decisions and ultimately the investment performance. Investors are unlikely to pick the stocks that they have adverse experiences with and choose the ones that have reported strong earnings in the past. Previous studies have demonstrated the positive and significant link between EQ and investment performance and decisions. Therefore, the main limitation of the study is the focus on investment performance and decisions. It provides a narrow scope of examining the effects of EQ and IQ on behavioral finance. The study has also had limited coverage of the potential biases likely to arise from the behavioral practices in investment decision-making. Future studies should expound on the possible biases that are likely to occur and affect investment performance.

\section{REFERENCES}

Ackert, L.F., Deaves, R., Miele, J., \& Nguyen, Q. (2020). Are time preference and risk preference associated with cognitive intelligence and emotional intelligence? Journal of Behavioral Finance, 21(2), 136-156. https://doi.org/10.1080/15427560.2019.1663850

Ady, S.U. (2018). The Cognitive and Psychological Bias in Investment Decision-Making Behavior (Evidence from Indonesian Investor's Behavior). Journal of Economics and Behavioral Studies, 10(1), 86-100. Retrieved from https://ifrnd.org/journal/index.php/jebs/article/view/2092/1585

Alquraan, T., Alqisie, A., \& Al Shorafa, A. (2016). Do behavioral finance factors influence the stock investment decisions of individual investors? (Evidence from Saudi Stock Market). American International Journal of Contemporary Research, 6(3), 159-169.

Awais, M., Laber, M.F., Rasheed, N., \& Khursheed, A. (2016). Impact of financial literacy and investment experience on risk tolerance and investment decisions: Empirical evidence from Pakistan. International Journal of Economics and Financial Issues, 6(1).

Barber, B.M., \& Odean, T. (2001). Boys will be boys: Gender, overconfidence, and common stock investment. The Quarterly Journal of Economics, 116(1), 261-292. https://doi.org/10.1162/003355301556400

Boda, J.R., \& Sunitha, G. (2018). Investor's psychology in investment decision making: A behavioral finance approach. International Journal of Pure and Applied Mathematics, 119(7), 1253-1261.

Browning, C., \& Finke, M. (2015). Cognitive ability and the stock reallocations of retirees during the Great Recession. Journal of Consumer Affairs, 49(2), 356-375. https://doi.org/10.1111/joca.12065

Charles, A., \& Kasilingam, R. (2014). Do Investors' Emotions Determine their Investment Personality? Parikalpana: KIIT Journal of Management, 10(2).

Christelis, D., Jappelli, T., \& Padula, M. (2010). Cognitive abilities and portfolio choice. European Economic Review, 54(1), 18-38. https://doi.org/10.1016/j.euroecorev.2009.04.001

Christie, A.M., Jordan, P.J., \& Troth, A.C. (2015). Trust antecedents: Emotional intelligence and perceptions of others. International Journal of Organizational Analysis, 23(1), 89-101. https://doi.org/10.1108/IJOA-07-2013-0695

Dhiman, B., \& Raheja, S. (2018). Do the personality traits and emotional intelligence of investors determine their risk tolerance? Management and Labor Studies, 43(1-2), 88-99.

https://doi.org/10.1177/0258042X17745184 
Disatnik, D., \& Steinhart, Y. (2015). Need for cognitive closure, risk aversion, uncertainty changes, and their effects on investment decisions. Journal of Marketing Research, 52(3), 349-359. https://doi.org/10.1509/jmr.13.0529

El-Chaarani, H. (2016). Exploring the impact of emotional intelligence on portfolio performance. performance. Humanomics, 32(4), 474-497. https://doi.org/10.1108/H-02-2016-0012

Fachrudin, K.R., \& Fachrudin, K.A. (2016). The influence of education and experience toward investment decisions with moderated by financial literacy. Polish Journal of Management Studies, 14. DOI 10.17512/pjms.2016.14.2.05

Fernandes, D., Lynch, J.G., Jr., \& Netemeyer, R.G. (2014). Financial literacy, financial education, and downstream financial behaviors. Management Science, 60(8), 1861-1883. https://doi.org/10.1287/mnsc.2013.1849

Hadi, F. (2017). Effect of emotional intelligence on investment decision making with a moderating role of financial literacy. China-USA Business Review, 16(2), 53-62. doi: 10.17265/1537$1514 / 2017.02 .002$

Janor, H., Yakob, R., Hashim, N.A., Zanariah, Z., \& Wel, C.A.C. (2017). Financial literacy and investment decisions in Malaysia and the United Kingdom: A comparative analysis. GeografiaMalaysian Journal of Society and Space, 12(2).

Korniotis, G.M., \& Kumar, A. (2011). Do older investors make better investment decisions? The Review of Economics and Statistics, 93(1), 244-265. https://doi.org/10.1162/REST_a_00053

Metawa, N., Hassan, M.K., Metawa, S., \& Safa, M.F. (2019). Impact of behavioral factors on investors' financial decisions: A case of the Egyptian stock market. International Journal of Islamic and Middle Eastern Finance and Management, 12(1), 30-55. https://doi.org/10.1108/IMEFM-122017-0333

Pak, O., \& Mahmood, M. (2015). Impact of personality on risk tolerance and investment decisions. International Journal of Commerce and Management, 24(4), 370-384. https://doi.org/10.1108/IJCoMA-01-2013-0002

Pirayesh, R. (2014). A study on the effect of emotional intelligence on retail investors' behavior. Management Science Letters, 4(1), 43-48. DOI: 10.5267/j.msl.2013.11.037

Sashikala, V., \& Chitramani, P. (2017). A review on emotional intelligence and investment behavior. International Journal of Management (IJM), 8(3).

Talpsepp, T., Liivamägi, K., \& Vaarmets, T. (2020). Academic abilities, education, and performance in the stock market. Journal of Banking \& Finance, 117, 105848. https://doi.org/10.1016/j.jbankfin.2020.105848

Tanvir, M., Sufyan, M., \& Ahsan, A. (2016). Investor's emotional intelligence and impact on investment decision. International Journal of Academic Research in Economics and Management Sciences, 5(3), 12-28. DOI:10.6007/IJAREMS/V5-I3/2237

Tariq, A., \& Hassan, A. (2017). Impact of risk perception on investment behavior, and the moderating role of emotional intelligence. International Journal of Public Finance, Law \& Taxation, 1(1). ISSN: 2581-3420

VanderPal, G. (2014). Global Leadership and Emotional Quotient. Journal of Applied Business and Economics, 16(5). 